\title{
Small-Animal PET: What Is It, and Why Do We Need It?*
}

\author{
Rutao Yao $^{1}$, Roger Lecomte ${ }^{2}$, and Elpida S. Crawford ${ }^{1}$ \\ ${ }^{I}$ Department of Nuclear Medicine, State University of New York at Buffalo, Buffalo, New York; and ${ }^{2}$ Department of Nuclear Medicine \\ and Radiobiology, Université de Sherbrooke, Sherbrooke, Quebec, Canada
}

\begin{abstract}
Small-animal PET refers to imaging of animals such as rats and mice using dedicated PET scanners. Small-animal PET has been used extensively in modern biomedical research. It provides a quantitative measure of the 3-dimensional distribution of a radiopharmaceutical administered to a live subject noninvasively. In this article, we will discuss the operational and technical aspects of small-animal PET; make some comparisons between small-animal PET and human PET systems; identify the challenges of, opportunities for, and ultimate limitations in applying small-animal PET; and discuss some representative small-animal PET applications. Education objectives: After reading this article, the technologist will be able to explain the requirements and benefits of small-animal PET in biomedical research, describe the design and general characteristics of a small-animal PET system, list and describe some of the challenges of imaging small animals, and discuss several small-animal PET applications.
\end{abstract}

Key Words: positron emission tomography (PET); animal imaging J Nucl Med Technol 2012; 40:157-165 DOI: 10.2967/jnmt.111.098632

\section{$\mathbf{S}$} rats and mice using a small, high-resolution PET scanner designed specifically for this purpose. Compared with a human PET scanner, a small-animal PET scanner is used for subjects that typically are 2 to 3 orders less in weight and volume than a human. The small structures of small animals require a scanner with high spatial resolution, ideally at submillimeter level, to identify the critical organs or target areas. As a reference, the spatial resolution of a state-of-the-art human PET system is in the range of 4$6 \mathrm{~mm}$. The volume resolution of small-animal PET is usually at the microliter level. This is one of several reasons that micro is used as part of the name of one commercial small-animal PET scanner (microPET; Siemens Preclinical Solutions). Because of the small size of the imaging sub-

\footnotetext{
Received Sep. 26, 2011; revision accepted Dec. 16, 2011.

For correspondence or reprints contact: Rutao Yao, Room 105, Parker Hall, 3435 Main St., Buffalo, NY 14214.

E-mail: rutaoyao@buffalo.edu

Published online May 11, 2012.

*NOTE: FOR CE CREDIT, YOU CAN ACCESS THIS ACTIVITY THROUGH THE SNM WEB SITE (http://www.snm.org/ce_online) THROUGH SEPTEMBER 2014.

COPYRIGHT @ 2012 by the Society of Nuclear Medicine and Molecular Imaging, Inc.
}

jects, a small-animal PET system has a detector gantry that is only a fraction the size of one in a human PET scanner. For example, typical small-animal PET systems have a detector ring diameter of approximately $150 \mathrm{~mm}$ (6 in), as compared with approximately $800 \mathrm{~mm}$ (31 in) for human PET systems. The smaller detector ring is advantageous in that it saves detector cost and also improves the geometric detection efficiency of the system. This is another reason that micro is part of the name of the Siemens system. In fact, it has become a convention that when micro is used as a prefix to an imaging modality, such as micro-CT and micro-MRI, it indicates small-animal imaging.

\section{GENERAL ROLE OF SMALL-ANIMAL PET}

The demand for small-animal PET is driven by the importance of animal model-based research. The mouse and the rat host a large number of human diseases. Collection of scientific data from these animal studies is important to medical research. For example, before a new drug is tried on patients, there must be extensive data from animal studies on such things as dose, biodistribution of the drug, route of administration and excretion, effectiveness for a clinical indication, and toxicity. Animal studies such as these provide preclinical data that must be submitted to the Food and Drug Administration as part of an Investigational New Drug Application, the regulatory step needed to move on to human clinical studies. Before the development of smallanimal PET, such preclinical data could be obtained only through sacrificing and dissecting the tissues of a large number of animals.

Since its emergence in the mid 1990s, small-animal PET has been used extensively in modern biomedical research (1). It can provide a quantitative measure of the 3-dimensional distribution of the radiopharmaceutical as a function of time in a live subject noninvasively (2-4). Compared with conventional invasive animal study techniques, such as tissue dissection, small-animal PET allows the entire dynamic biodistribution of a labeled compound to be measured in the same subject in a single scan and, additionally, enables a single animal to be studied multiple times over the course of the evaluation. Not only is there an effective reduction in the number and cost of laboratory animals used in experiments, but most importantly, there is the potential to reduce drug development costs by readily providing pharmacokinetic data. The primary advantage of small-animal PET, compared with small-animal CT and MRI, is that 
it allows us to study physiologic processes and molecular abnormalities that are the basis of disease rather than just image the end effects of cellular and molecular alterations. Imaging of specific molecular targets with small-animal PET enables earlier detection and characterization of disease, earlier and direct molecular assessment of treatment effects, and a more fundamental understanding of disease processes. As such, small-animal PET is, together with clinical PET, a key instrument in the development and implementation of personalized medicine.

The primary use of animal PET is concentrated in academic or government research laboratories (70\%$80 \%$ ), with the remainder being in pharmaceutical and biopharmaceutical companies. On the research laboratory side, the demand for small-animal PET has been driven by the strategic plans of government agencies such as the National Institutes of Health and the Food and Drug Administration, the largest U.S. financier of basic research and the governing U.S. body of all clinical drugs, respectively. For the pharmaceutical industry, a significant benefit of small-animal PET is that it can bridge the gap between preclinical "pharmaceutical" studies in animals and phase I trials in humans. By allowing in vivo pharmacokinetic and pharmacodynamic studies, small-animal PET permits studies of administration, distribution, metabolism, and excretion to be performed much more easily and quickly. Small-animal PET allows faster screening of investigational compounds and earlier decisions about a compound's suitability, thus potentially accelerating the new drug development cycle at reduced cost. Small-animal PET also provides the opportunity to study disease progression, therapeutic response, and secondary detrimental effects in the same subject.

\section{GENERAL INFORMATION ABOUT SMALL-ANIMAL PET}

The first small-animal PET scanners were developed about 20 y ago (5-10). Since then, both the technology and the user base of small-animal PET have experienced phenomenal growth. There are currently a few hundred smallanimal PET systems already installed. As an example of user base growth, there were 20 research presentations that used small-animal PET at the Society of Nuclear Medicine annual meeting in 2000 and the number increased to 143 in 2007 (11). On the technology development side, small-animal PET has been an active research topic since its emergence $(12,13)$. This continued endeavor has established the knowledge base for small-animal PET technology. Several small-animal PET systems developed in laboratories have advanced to become commercial products. Figure 1 shows a small-animal PET scanner.

A list of commercially available small-animal PET systems can be found in Table 1. Only brief system specifications are provided in the table, but a more extensive systematic evaluation of several of these systems can be found in a recent report (14). Like clinical PET scanners, small-animal PET systems implement 3-dimensional data acquisition in list mode (i.e., events recorded individually

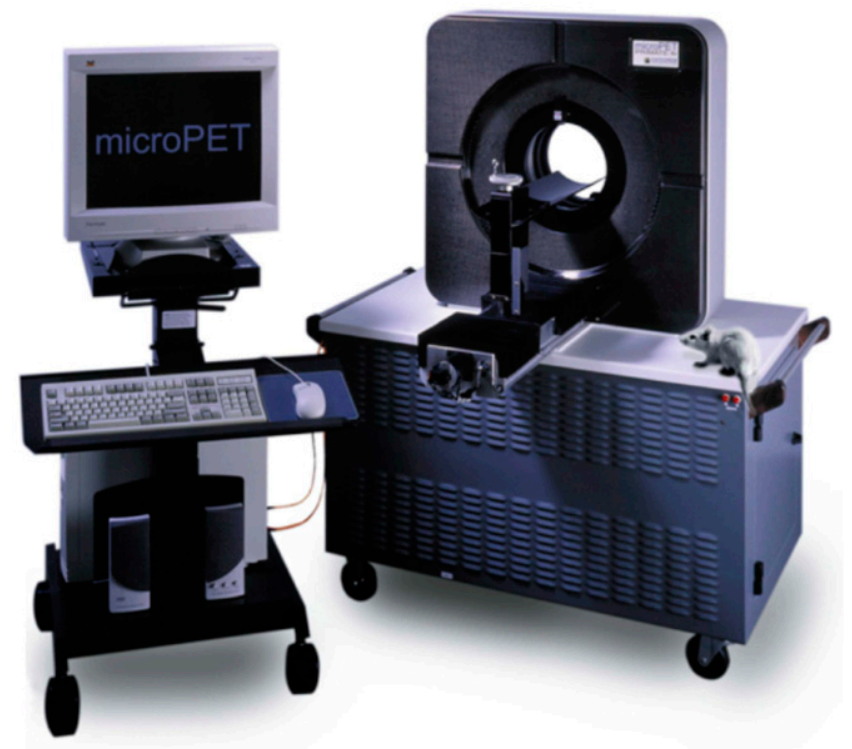

FIGURE 1. Photograph of microPET Focus 120 scanner (Siemens Preclinical Solutions). (Courtesy of Maurice M. Weaver.)

without charting as histograms) to enable image time framing and provide physiologic gating inputs to correct for cardiac and respiratory motion. All small-animal PET systems use photomultiplier-based detector technologies, except one, the LabPET (Gamma Medica/GE Healthcare), which uses semiconductor avalanche photodiode-based detectors (15). Most systems today are offered in combination with a small-animal CT scanner for coregistration of the anatomic image with the PET data. The price for different small-animal PET systems ranges between $\$ 400,000$ and $\$ 1,200,000$, depending on the PET system configuration. Among the commercial small-animal PET manufacturers, Siemens Preclinical Imaging has a greater selection of system models and owns more than $50 \%$ of the world's market share of small-animal PET scanners. The globalization of the economy and science has also triggered the fast proliferation of small-animal PET in emerging development countries and regions such as South Korea, Taiwan, and China.

\section{UNIQUE CHARACTERISTICS OF SMALL-ANIMAL PET}

Small-animal PET and human PET both use similar image formation techniques and share some common image quality issues. But small-animal PET has some unique characteristics and faces special challenges that stem from the much smaller imaging subject used in studies. The challenges of small-animal systems are discussed below.

\section{Small-Animal Imaging}

Rats and mice are not as cooperative as humans. Rodents do not remain still through an imaging session that usually lasts tens of minutes. Anesthesia must be used for most imaging procedures. Anesthesia is preferably performed 
TABLE 1

Commercially Available Small-Animal PET Scanners and Their Key System Specifications

\begin{tabular}{|c|c|c|c|c|c|c|c|}
\hline \multirow[b]{3}{*}{ Manufacturer } & \multirow[b]{3}{*}{ Model } & \multirow{2}{*}{\multicolumn{2}{|c|}{ FOV (mm) }} & \multicolumn{3}{|c|}{ At CFOV... } & \multirow[b]{3}{*}{ Reference } \\
\hline & & & & \multirow{2}{*}{$\begin{array}{l}\text { FWHM spatial } \\
\text { resolution }(\mathrm{mm})\end{array}$} & \multirow{2}{*}{$\begin{array}{c}\text { Sensitivity } \\
(\%)\end{array}$} & \multirow{2}{*}{$\begin{array}{l}\text { Energy window } \\
\text { (keV) }\end{array}$} & \\
\hline & & Transaxial & Axial & & & & \\
\hline Bioscan/Mediso & NanoPET & $45-123$ & 94 & 1.2 & 8.3 & $250-750$ & (69) \\
\hline Carestream & Albira & 80 & $40-148$ & $<1.3$ & $3-9$ & Not available & (70) \\
\hline $\begin{array}{l}\text { Gamma Medica/GE } \\
\text { Healthcare }\end{array}$ & LabPET & 110 & $38-113$ & 1.3 & $1.1-5.4$ & $250-650$ & (15) \\
\hline Philips & Mosaic HP & 128 & 120 & 2.7 & 1.1 & $410-665$ & (71) \\
\hline $\begin{array}{l}\text { Raytest } \\
\text { Isotopenmessgeräte } \\
\text { GmbH }\end{array}$ & ClearPET & 94 & 110 & 1.5 & 1.9 & $250-750$ & (72) \\
\hline Sedecal, S.A. & rPET-1 & 68 & 47 & 1.5 & 0.5 & $250-650$ & (72) \\
\hline \multirow[t]{3}{*}{$\begin{array}{l}\text { Siemens Preclinical } \\
\text { Solutions }\end{array}$} & $\begin{array}{l}\text { microPET } \\
\text { Focus } 120\end{array}$ & 100 & 76 & 1.3 & 7.1 & $250-750$ & (73) \\
\hline & $\begin{array}{l}\text { microPET } \\
\text { Focus } 220\end{array}$ & 190 & 76 & 1.3 & 3.4 & $250-750$ & (74) \\
\hline & $\begin{array}{l}\text { microPET } \\
\text { Inveon DPET }\end{array}$ & 100 & 127 & 1.4 & 9.3 & $250-625$ & (32) \\
\hline
\end{tabular}

$\mathrm{CFOV}=$ center field of view

through masking the animal with a mixture of isoflurane and oxygen gases. Because of their smaller bodies, the physiologic conditions of mice and rats are more susceptible to environmental changes and hypothermia during the imaging process. To warrant the reliability and reproducibility of PET data, especially when physiologic parameters such as blood flow, substrate metabolism, or organ functions are being investigated, a heating source (light bulb, air flow, or pad) must be used to maintain the animal's body temperature, and vital signs must be monitored to verify the animal's homeostasis. These measures are also important to ensure that the animal remains in a fully recoverable physical state through several imaging sessions. To ensure consistency during a longitudinal study, certain devices are commonly used to hold the animals in selected positions. Figure 2 shows an imaging chamber used to help restrain the animal while providing anesthesia and oxygen gas during image acquisition.

\section{Constraints on Tracer Mass, Volume, and Radioactivity}

The tracer mass injected into a small animal must be sufficiently low that the natural physiologic state of the animal is not affected. The rule of thumb is that the tracer

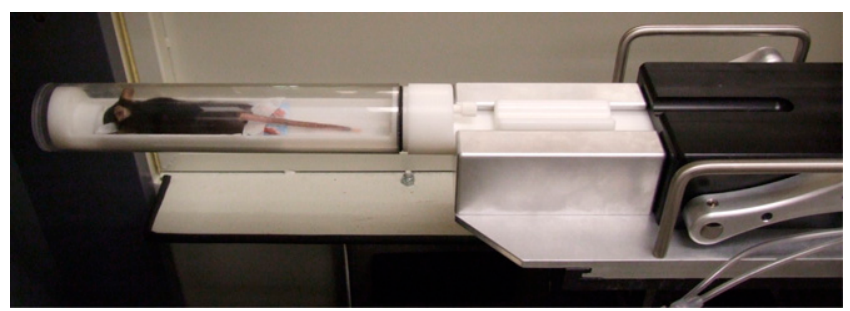

FIGURE 2. Mouse is placed in tube designed to facilitate anesthesia and positioning consistency. (Courtesy of David B. Stout.) mass will cause a maximal receptor occupancy of $1 \%$. Because the tracer specific activity $(\mathrm{Bq} / \mathrm{g})$ is typically fixed, the allowed tracer activities are limited. For example, it was estimated that the maximal injected radioactivity of ${ }^{11} \mathrm{C}$ labeled raclopride, a PET ligand for $\mathrm{D}_{2}$-dopamine receptor, is $5.2 \mathrm{MBq}$ in rats and $0.3 \mathrm{MBq}$ in mice (16). Another constraint on the use of radiotracers in small animals is that the injection volume should be less than $10 \%$ of the animal's total blood volume, which is 30 and $2.5 \mathrm{~mL}$, respectively, for rats and mice. Hence, the commonly used tracer dilution for clinical applications in humans may not be appropriate and sometimes needs to be adapted for smallanimal imaging.

\section{Spatial Resolution}

The spatial resolution of a small-animal PET scanner depends on 4 factors of the system design (17): the size of the detector crystal; the detectors' decoding scheme, which determines the particular location in which photons interact with the detector; the positron's movement range after its emission and before annihilation; and the annihilation photons' absence of colinearity, which is intrinsic to the annihilation physics. After $20 \mathrm{y}$ of intensive research and development (12), the best resolution reported for smallanimal PET systems has been about $1 \mathrm{~mm}$ in full width at half maximum (18).

The primary advancement factor that leads to the very high resolution of recent small-animal PET scanners is the use of long and thin detector crystals, with the long side aligned with the radial direction and the narrow side facing the imaging field of view. A drawback is the higher probability that the detected photons are not from the headon projection but from the side (oblique) projections by penetrating the neighboring crystals. As illustrated in 
Figure 3, the detector responses (the gray shades between the 2 crystals of the coincident event) are narrow for headon projections and become wider for oblique projections. This effect, also known as parallax error, can be mitigated through the use of a few short crystals to replace each single long crystal (19-21) or by measurement of the depth of interaction within the crystal $(22,23)$. Alternatively, the spatially variant detector response functions are modeled in the reconstruction algorithm $(24,25)$ to achieve resolution recovery for the oblique projections emanating from off-center regions. The use of a statistical iterative reconstruction algorithm such as ordered-subset expectation maximization, which allows the incorporation of an accurate system response model, is a major advantage of the newer generation of small-animal PET scanners.

It is informative to have a comparison of the spatial resolutions of small-animal PET and human PET systems. The weight of a typical mouse is about $25 \mathrm{~g}$. Compared with an average-sized adult, weighing $75 \mathrm{~kg}$, the mouse is scaled down by a factor of 3,000 in weight and about 15 in size. For a 300-g rat, the weight and size scale-down factors are 250 and 6, respectively. To visualize the same level of structural detail in a mouse, compared with a human, the small-animal PET system needs to have a spatial resolution 15 times better than a human PET system. Given that state-of-the-art human PET systems achieve a spatial resolution of $6 \mathrm{~mm}$, smallanimal PET would need to have a spatial resolution of 0.4 $\mathrm{mm}$ for mouse imaging and $1 \mathrm{~mm}$ for rat imaging to distinguish the same level of structural detail in the images. As shown in Table 1, the current resolution limit of commercial small-animal PET systems is slightly more than $1 \mathrm{~mm}$, whereas experimental prototypes achieve slightly less than $1 \mathrm{~mm}(23,26-30)$. Therefore, the resolution capability of small-animal PET is close to what is needed for rat imaging but not yet fully optimal for mouse imaging.

\section{System Sensitivity}

As is the case with other nuclear medicine imaging systems, the sensitivity of a small-animal PET system is

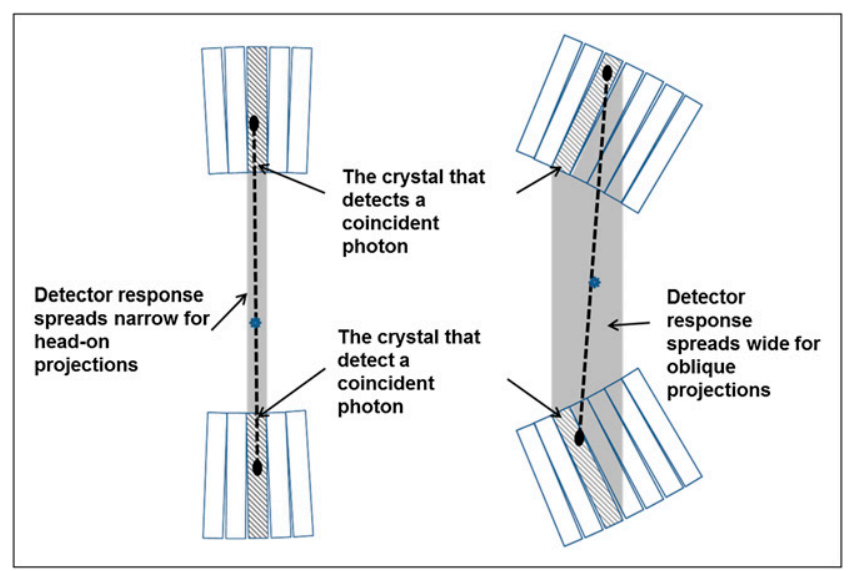

FIGURE 3. Diagram illustrating difference between head-on and oblique projections in terms of detector response spread (shaded area between crystals detecting coincidence event). primarily a measure of its efficiency in collecting the emission photons emanating from the animal. The system detection efficiency, commonly designated as absolute sensitivity, can be reported as counting rate per unit radioactivity in the scanner field of view (cps/Bq) or simply as percentage. Higher detection efficiency leads to a greater number of detected events, which usually will shorten image acquisition time.

Most small-animal PET systems use a cylindric geometry as used in human PET. Because of the relatively smaller diameter of the detector ring, small-animal PET developers are able to expand the detector rings in the axial direction and still have a number of detector channels similar to that used for human PET (31). For example, the Inveon (Siemens Preclinical Solutions) has 25,600 detector crystals (32) and the PET modules of the Biograph PET/CT system (Siemens) have 32,448 detector crystals (33). Stateof-the-art small-animal PET systems' highest reported absolute sensitivity at the center of the field of view is approximately $10 \%$, which is about 3 times that of a conventional human PET scanner.

\section{Scatter and Attenuation Contributions to Image Quantification}

Mice and rats are much smaller than humans. As represented by the standard phantoms used in National Electrical Manufacturers Association standards $(34,35)$ for small-animal PET and human PET, the diameters of the polyethylene phantom cylinders for emulating mice, rats, and humans, respectively, are 25, 50, and $203 \mathrm{~mm}$. For this reason, the amount of scattered events and the magnitude of attenuation are both much less in small-animal PET than in human PET. By simple calculation, the fractions of photons transmitted through the length of the cylinder diameter for the mouse, rat, and human phantoms are $79 \%, 62 \%$, and $14 \%$, respectively. The typical values of scatter fractions reported are $8 \%$ and $17 \%$ for mouse and rat phantoms, respectively (32), as compared with 33\% for human PET (36). So the scatter and attenuation issues are less significant for small-animal PET than for human PET $(37,38)$. When only qualitative or semiquantitative results are required, scatter and attenuation corrections may be skipped in small-animal PET studies.

Small-animal PET scanners are usually equipped with attenuation and scatter correction techniques that are the same as those for human PET in principle $(39,40)$. When quantitative animal PET is required, a transmission or CT scan is included in the data acquisition protocol, and attenuation and scatter corrections are enabled in the image generation protocol.

\section{Small-Animal PET and Multimodality Imaging}

Since the late 1990s, a major research and development theme in the medical imaging community has been to explore the complementary roles of individual modalities and to promote and harness the power of combining several technologies into a single system or unit (41). Small-animal 
PET is an essential member of the multimodality microimaging family. Because of its high sensitivity and molecular imaging capability, it is ideally suited for combination with small-animal CT or MRI in providing complementary anatomic and functional information on the animal under investigation. When combined with optical imaging systems, which can image only targets near the body surface, small-animal PET's capability of studying deep organs is most valuable.

Small-animal PET requires substantial supporting resources and equipment, such as cyclotron and PET radiochemistry facilities, to be fully exploited. Therefore, to achieve and make best use of the synergy of multimodality imaging, as well as to share the significant cost it incurs, core imaging facilities that host several microimaging systems are usually set up by large research institutes at a centralized location to provide services to the researchers in the vicinity (42).

\section{EXAMPLES OF SMALL-ANIMAL PET APPLICATIONS}

Applications of small-animal PET have been reported over a wide range of biologic processes (43). Here we present examples of small-animal PET applications in each of the 3 primary disease areas: oncology, cardiology, and neurology. Readers who are interested in more complete descriptions of small-animal PET applications are referred to a few excellent review articles (2-4).

\section{Oncology}

Cancer is the primary application of small-animal PET $(3,44,45)$. Table 2 provides a few samples of common tracers and their targeted mechanisms used for oncology applications. Of these, glucose metabolism monitored with ${ }^{18} \mathrm{~F}$-FDG is the one in greatest use clinically (46). There exist many other targeted mechanisms, such as tumor cell proliferation (47), gene expression $(48,49)$, tumor angiogenesis (50), tumor hypoxia $(51,52)$, and tumor apoptosis $(53,54)$.
Figure 4 shows an example of a small-animal PET study for evaluating a new agent for both cancer diagnosis and treatment. The ${ }^{18} \mathrm{~F}$-FDG image was acquired as a reference to evaluate the agent as a diagnostic and therapy follow-up tracer. The same mouse was then injected with a ${ }^{124} \mathrm{I}$-labeled derivative of pyropheophorbide-a, which is an imaging and photodynamic therapy bifunctional agent. Because of the long half-life of the ${ }^{124} \mathrm{I}$ (4.2 d), a longitudinal study (multiple scans over time) was possible with the same mouse and the same agent. The mouse was imaged at 4 time points over $3 \mathrm{~d}$. The tumor uptake relative to the rest of the body increased over time, indicating that the agent has promising potential as both a therapeutic and a tumor-monitoring agent.

\section{Cardiology}

Small-animal PET has been used to study cardiac physiology, metabolism, and conditions similar to those in human and large-animal cardiac investigations. Imaging techniques to minimize wall motion effects such as electrocardiogram-gated data acquisitions and the corresponding image analysis approaches developed for human PET and SPECT cardiology can be used on rat or mouse images. Figure 5 shows an example of small-animal PET imaging of the cardiac functions of a normal rat and a rat with a region of myocardial infarction (55). Both rats were injected with ${ }^{18}$ F-FDG. The data were acquired in list mode and included both electrocardiogram gating and time markers. The normal-rat images depict homogeneous radiotracer distribution in the myocardium and a high ejection fraction. The images of the diseased rat myocardium demonstrate an uptake defect in the anterolateral segment, remodeling of the myocardium muscle, and a reduced ejection fraction. With gating, the image blurring due to cardiac motion was eliminated, and higher image contrast and def-

TABLE 2

Sample PET Tracers Used in Oncology

\begin{tabular}{|c|c|c|}
\hline Target pathophysiology & Tracer & Working principle \\
\hline $\begin{array}{l}\text { Metabolism } \\
\text { (glycolysis) }\end{array}$ & ${ }^{18} \mathrm{~F}-\mathrm{FDG}$ & $\begin{array}{l}\text { Uptake and metabolism: tumor cells have higher } \\
\text { rate of glucose, to which }{ }^{18} \mathrm{~F}-\mathrm{FDG} \text { is analog. }\end{array}$ \\
\hline Cell proliferation & $\begin{array}{l}3^{\prime}-\text { deoxy-3' }-{ }^{18} \text { F-fluorothmidine } \\
\left({ }^{18} \mathrm{~F}-\mathrm{FLT}\right)\end{array}$ & $\begin{array}{l}\text { Malignant transformation increases cell } \\
\text { proliferation, which upregulates thymidine. }\end{array}$ \\
\hline Gene expression & $\begin{array}{l}\text { 9-(4-fluoro- }{ }^{18} \mathrm{~F}-3-\text { hydroxymethylbutyl) } \\
\left.\text { guanine ( }{ }^{18} \mathrm{~F}-\mathrm{FHBG}\right)\end{array}$ & $\begin{array}{l}\text { Radiolabeled probe is phosphorylated by selected } \\
\text { gene product and is trapped within cell. Thus, } \\
\text { magnitude of probe accumulation in cell reflects } \\
\text { level of gene expression. }\end{array}$ \\
\hline Tumor angiogenesis & ${ }^{89} \mathrm{Zr}$-bevacizumab & $\begin{array}{l}\text { Vascular endothelial growth factor (VEGF) plays pivotal roles } \\
\text { in regulating tumor angiogenesis. }{ }^{89} \mathrm{Zr} \text {-bevacizumab is } \\
\text { anti-VEGF antibody and binds to VEGF. }\end{array}$ \\
\hline Hypoxia & ${ }^{18} \mathrm{~F}$-fluoromisonidazole ( ${ }^{18} \mathrm{~F}$-FMISO) & $\begin{array}{l}\text { Rapid tumor growth leads to underdeveloped new } \\
\text { vascularization, which creates hypoxia. }{ }^{18} \mathrm{~F}-\mathrm{FMISO} \text { takes } \\
\text { advantage of increased tracer retention in hypoxic tissues } \\
\text { with partial pressure of oxygen }<10 \mathrm{~mm} \mathrm{Hg} \text {. }\end{array}$ \\
\hline Apoptosis & $\begin{array}{l}{ }^{18} \text { F-fluorobenzyl triphenylphosphonium } \\
\left.\text { cation ( }{ }^{18} \mathrm{~F}-\mathrm{FBnTP}\right)\end{array}$ & $\begin{array}{l}\text { Apoptosis involves permanent collapse of } \\
\text { mitochondrial membrane electrochemical potential. } \\
{ }^{18} \mathrm{~F}-\mathrm{FBnTP} \text { is voltage-sensitive probe. }\end{array}$ \\
\hline
\end{tabular}


FIGURE $4 .{ }^{18} \mathrm{~F}-\mathrm{FDG}$ image on left (coronal view) was acquired first as reference $90 \mathrm{~min}$ after injection of 9.4 $\mathrm{MBq}(254 \mu \mathrm{Ci})$ of activity via tail vein of tumor-bearing $\mathrm{C} 3 \mathrm{H}$ mouse. Mouse was then injected with $2.7 \mathrm{MBq}(72 \mu \mathrm{Ci})$ of ${ }^{124} \mathrm{I}-$ labeled derivative of pyropheophorbide-a, a bifunctional diagnostic and therapeutic agent (75). Mouse was imaged for $30 \mathrm{~min}$
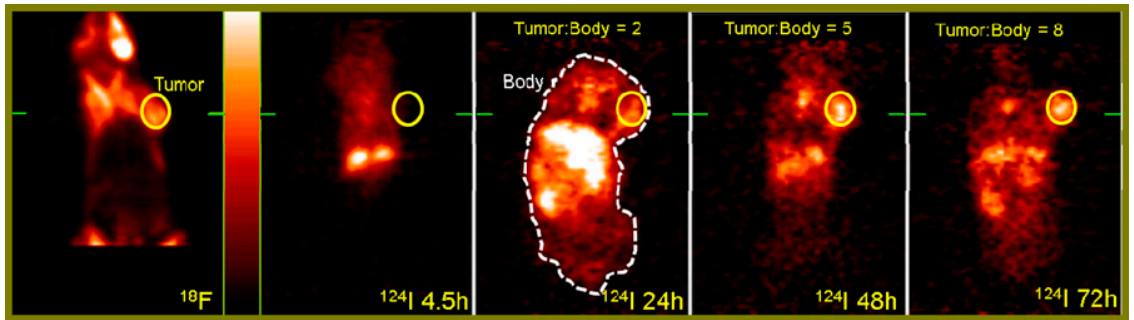
at $4.5,24,48$, and $72 \mathrm{~h}$ after injection.

Concentration ratios of bifunctional agent in tumor (solid-line circle in each image) to that in animal body (dashed outline in middle image) were 2, 5, and 8 at 24, 48, and $72 \mathrm{~h}$ after injection, respectively, indicating that agent has desired properties to be used in therapeutic and monitoring applications. Color palette (shown to right of ${ }^{18} \mathrm{~F}$ image) was scaled to minimum/maximum of transverse slice passing through center of tumor site (indicated by green bars) in each dataset. Display scheme was same for all images. ${ }^{18} \mathrm{~F}={ }^{18} \mathrm{~F}-\mathrm{FDG}$; $124 \mathrm{I}={ }^{124} \mathrm{I}$-pyropheophorbide derivative.

inition were achieved. As a result, it was possible to better appreciate myocardial wall thickness because of minimization of wall motion and to distinguish the right ventricle, which statistically has much lower signal strength than the left ventricle (55). QGS (56), a quantitative analysis package initially developed for SPECT but validated for PET (57) cardiac imaging, was used to reorient the gated image sequences and obtain quantitative cardiac function parameters such as end-diastolic and end-systolic ventricular volumes, stroke volume, left ventricular ejection fraction, and polar maps of enddiastolic and end-systolic tracer distribution, wall thickening, and wall motion.

\section{Neurology}

Over the years, a wide selection of PET radiotracers has been developed for brain imaging, such as $\mathrm{H}_{2}{ }^{15} \mathrm{O}$ for measuring cerebral blood flow, ${ }^{18} \mathrm{~F}-\mathrm{FDG}$ for measuring glucose metabolism, ${ }^{11} \mathrm{C}$-raclopride for quantifying the postsynaptic $\mathrm{D}_{2}$ receptor level, ${ }^{11} \mathrm{C}$-Pittsburgh compound $\mathrm{B}$ for imaging $\beta$-amyloid deposition, and the radioligand ${ }^{11} \mathrm{C}-(R)-(-)-$ RWAY for studying brain 5-hydroxytryptamine receptor 1A. Using these tracers, small-animal PET has many applications for studying the pathophysiology, pharmacology, and drug mechanisms of the brain (58).

Figure 6 is an example of a small-animal PET application in neuropharmacology. The study was to quantify how Pglycoprotein (an efflux pump at the blood-brain barrier) and its blockade with cyclosporin A affect rat brain uptake of ${ }^{11} \mathrm{C}-(R)-(-)$-RWAY $(59)$. Figures 6A and 6B show a coronal rat brain image of ${ }^{11} \mathrm{C}-(R)-(-)$-RWAY uptake in which 2 regions of interest were placed on the left and right hippocampi in reference to the rat brain atlas. The regionof-interest time-activity data of the hippocampi, acquired for $100 \mathrm{~min}$ after injection and framed with nonuniform time intervals, were then used for kinetic modeling. Figures 6C and $6 \mathrm{E}$ show the total-brain images of the control and cyclosporin A-treated rats, respectively. It is clear that when the efflux of the P-gp was blocked with cyclosporin $\mathrm{A}$, the rat brain uptake of ${ }^{11} \mathrm{C}-(R)-(-)$-RWAY increased significantly. This is also confirmed by the parametric images of binding potential shown in Figures $6 \mathrm{D}$ and $6 \mathrm{~F}$, obtained by kinetic modeling.

\section{CUTTING-EDGE SMALL-ANIMAL PET DEVELOPMENTS}

Although small-animal PET has established its position in molecular imaging, many exciting new technologic developments are bringing the methodology to the next level. A few current hot topics are described here to provide a glimpse of the near future of small-animal PET.

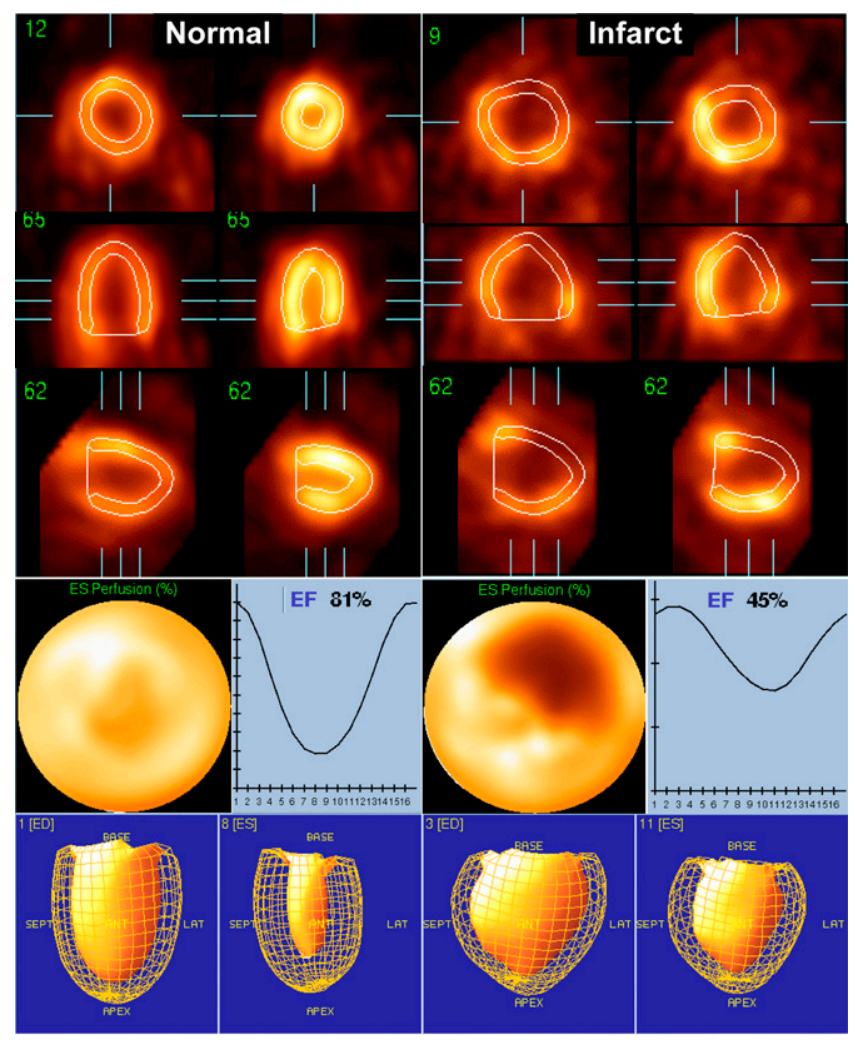

FIGURE 5. Electrocardiogram-gated ${ }^{18} \mathrm{~F}-\mathrm{FDG}$ studies in normal and infarcted rats obtained using clinical cardiac analysis software QGS (56). Polar maps display end-systolic ${ }^{18} \mathrm{~F}-\mathrm{FDG}$ uptake. Ejection fractions for normal and infarcted rats are $81 \%$ and $45 \%$, respectively. ED = end-diastolic; EF = ejection fraction; ES = end-systolic. (Adapted with permission of (55).) 


\section{ROI (Hippocampus)}

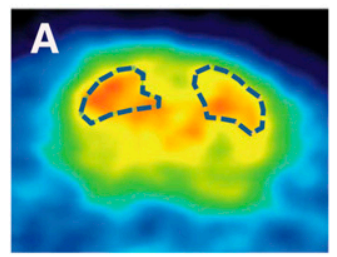

Rat Atlas

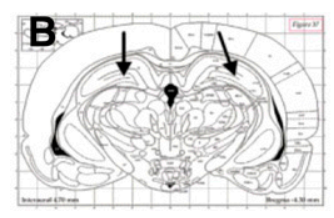

Forebrain (Total Image)

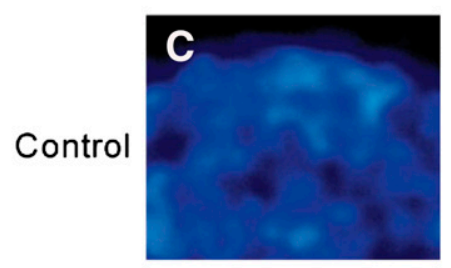

CsA
Hippocampus

( $B P$ Image)
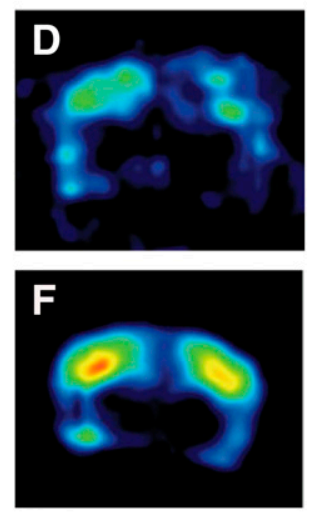

FIGURE 6. Uptake of ${ }^{11} \mathrm{C}-(R)-(-)$-RWAY in rat brain. Regions of interest were placed on left and right hippocampi (A), using coronal PET images with reference to rat brain atlas (B). Total uptake of radioactivity is shown in control rats $(C)$ and cyclosporin A-treated rats (E). Similarly, binding potential images are shown in control rats (D) and cyclosporin A-treated rats $(F)$. Cyclosporin A treatment significantly boosted uptake of ${ }^{11} \mathrm{C}-(R)$ $(-)$-RWAY, indicating blockade of efflux pump at blood-brain barrier. $B P=$ binding potential; CsA = cyclosporin A; $\mathrm{ROI}=$ region of interest. (Reprinted with permission of (59).)

\section{Imaging of Freely Moving Rodents}

The standard small-animal PET setup is that the subject rodent lies on an animal bed within a fixed small-animal PET gantry. The rodent, ideally, remains still throughout the imaging procedure. Any partial or whole-body motion would cause displacement of detected events and therefore undermine image quality. Although it is well known that forced immobilization or anesthesia of the animal can lead to unusual physiologic responses that may affect the experimental results, for lack of better alternatives these 2 approaches have been the only means to minimize animal movement until recently.

Two revolutionary better alternatives have just emerged (60). The first is enabled by an exquisitely engineered smallanimal PET scanner that a rat can wear $(61,62)$. Weighing a mere $250 \mathrm{~g}$, the detector ring and front-end electronics of the scanner are fitted to the head of a rat and attached to an animal mobility system that supports the weight of the scanner and allows the rat to move freely around a $40 \times 40 \mathrm{~cm}$ behavioral chamber while PET images are acquired. The second (62) involves a small-animal PET detector system that surrounds a chamber, and a precise and continuous tracking system that allows the position of the rodent's head within the chamber to be measured over time. The animal roams in the chamber during an imaging session. For image reconstruction, the tracking information is used to align the detected PET events to form a coherent animal body volume.

These 2 new techniques open a noninvasive window for assessing brain function and behavior in response to a wide variety of interventions in freely moving, nonanesthetized rodents.

\section{Integration with Small-Animal MRI}

The integration of PET and CT in both clinical and preclinical imaging settings has demonstrated the synergism of strengths achieved through the fusion of anatomic and functional imaging. Using the same strategy but with distinct new advantages, the integration of PET with MRI is the latest breakthrough in multimodality imaging developments (63). Compared with CT, MRI has 3 critical advan- tages: superior soft-tissue contrast, simultaneous imaging with small-animal PET, and freedom from ionizing radiation. These advantages make integrated PET/MRI and integrated small-animal PET/MRI an enabling technology for creating a new field in molecular and cellular imaging $(64,65)$. Knowledge of various metabolic and functional parameters measured at the same time as anatomy may open new insights into the organization of the brain and its changes in disease (66).

For example, integrated small-animal PET/MRI may be used to assess cell replacement approaches for treatment of various neurologic disorders. First, the grafted stem cells are labeled with MRI contrast-enhancing agents (ultra-small superparamagnetic iron oxide particles and micron-sized iron oxide particles) (67). Then, over the therapy assessment period, the migration of the transplanted cells can be imaged in the morphologic context of MRI, and the viability and function of the transplanted cells can be imaged in the functional context of PET (68).

\section{CONCLUSION}

Small-animal PET has exquisite sensitivity and the ability to provide quantitative, in vivo measurements of physiology, metabolic pathways, and molecular targets deep inside tissue. Over the last $15 \mathrm{y}$, this imaging technique has become a critically important tool in animal-based biomedical research. The application of small-animal PET has been expanded into many additional clinical indications. Its importance has been further enhanced by integration with other small-animal imaging modalities such as CT and MRI. Its unique role in leading clinical PET system development will advance PET technology to exciting new discoveries.

\section{ACKNOWLEDGMENT}

No potential conflict of interest relevant to this article was reported. 


\section{REFERENCES}

1. Schnöckel U, Hermann S, Stegger L, et al. Small-animal PET: a promising, noninvasive tool in pre-clinical research. Eur J Pharm Biopharm. 2010;74:50-54.

2. Cherry SR. In vivo molecular and genomic imaging: new challenges for imaging physics. Phys Med Biol. 2004;49:R13-R48.

3. Gambhir SS. Molecular imaging of cancer with positron emission tomography. Nat Rev Cancer. 2002;2:683-693.

4. Phelps ME. Positron emission tomography provides molecular imaging of biological processes. Proc Natl Acad Sci USA. 2000;97:9226-9233.

5. Cutler PD, Cherry SR, Hoffman EJ, Digby WM, Phelps ME. Design features and performance of a PET system for animal research. J Nucl Med. 1992;33:595-604.

6. Watanabe $\mathrm{M}$, Uchida $\mathrm{H}$, Okada $\mathrm{H}$, et al. A high-resolution PET for animal studies. IEEE Trans Med Imaging. 1992;11:577-580.

7. Lecomte R, Cadorette J, Rodrigue S, et al. Initial results from the Sherbrooke avalanche photodiode positron tomograph. IEEE Trans Nucl Sci. 1996;43:1952-1957.

8. Cherry SR, Shao Y, Silverman RW, et al. MicroPET: a dedicated PET scanner for small animal imaging [abstract]. J Nucl Med. 1996;37(suppl):334-334.

9. Bloomfield PM, Rajeswaran S, Spinks TJ, et al. The design and physical characteristics of a small animal positron emission tomograph. Phys Med Biol. 1995;40: 1105-1126.

10. Jeavons AP, Chandler RA, Dettmar CAR. A 3D HIDAC-PET camera with sub-millimetre resolution for imaging small animals. IEEE Trans Nucl Sci. 1999;46:468-473.

11. Wagner HN. Molecular imaging: thriving all over the world. J Nucl Med. 2007;48(8):15N

12. Tai YC, Laforest R. Instrumentation aspects of animal PET. Annu Rev Biomed Eng. 2005; 7:255-285.

13. Lecomte R. Technology challenges in small animal PET imaging. Nucl Instrum Methods Phys Res A. 2004;527:157-165.

14. Goertzen AL, Bao Q, Bergeron M, et al. NEMA NU4-2008 comparison of preclinical PET imaging systems. J Nucl Med. In press.

15. Bergeron M, Cadorette J, Beaudoin JF, et al. Performance evaluation of the LabPET APD-based digital PET scanner. IEEE Trans Nucl Sci. 2009;56:10-16.

16. Hume SP, Gunn RN, Jones T. Pharmacological constraints associated with positron emission tomographic scanning of small laboratory animals. Eur J Nucl Med. 1998;25:173-176.

17. Derenzo SE, Moses WW, Huesman RH, Budinger TF, eds. Critical instrumentation issues for resolution smaller than $2 \mathrm{~mm}$, high sensitivity brain PET. In: Uemura K, Lassen NA, Jones T, Kanno I, eds. Quantification of Brain Function. Tracer Kinetics and Image Analysis in Brain PET. Amsterdam, The Netherlands: Elsevier; 1993:25-37.

18. Peng H, Levin CS. Recent developments in PET instrumentation. Curr Pharm Biotechnol. 2010;11:555-571.

19. de Jong HWAM, van Velden FHP, Kloet RW, Buijs FL, Boellaard R, Lammertsma AA. Performance evaluation of the ECAT HRRT: an LSO-LYSO double layer high resolution, high sensitivity scanner. Phys Med Biol. 2007;52: 1505-1526.

20. Pomper MG, Wang YC, Seidel J, Tsui BMW, Vaquero JJ. Performance evaluation of the GE Healthcare eXplore VISTA dual-ring small-animal PET scanner. J Nucl Med. 2006;47:1891-1900.

21. Rafecas M, Boning G, Pichler BJ, Lorenz E, Schwaiger M, Ziegler SI. A Monte Carlo study of high-resolution PET with granulated dual-layer detectors. IEEE Trans Nucl Sci. 2001;48:1490-1495.

22. Shao YP, Yao RT, Ma TY. A novel method to calibrate DOI function of a PET detector with a dual-ended-scintillator readout. Med Phys. 2008;35:58295840 .

23. St James S, Yang YF, Wu YB, et al. Experimental characterization and system simulations of depth of interaction PET detectors using $0.5 \mathrm{~mm}$ and $0.7 \mathrm{~mm} \mathrm{LSO}$ arrays. Phys Med Biol. 2009;54:4605-4619.

24. Panin VY, Kehren F, Michel C, Casey M. Fully 3-D PET reconstruction with system matrix derived from point source measurements. IEEE Trans Med Imaging. 2006;25:907-921.

25. Selivanov VV, Picard Y, Cadorette J, Rodrigue S, Lecomte R. Detector response models for statistical iterative image reconstruction in high resolution PET. IEEE Trans Nucl Sci. 2000;47:1168-1175.

26. Rouze NC, Schmand M, Siegel S, Hutchins GD. Design of a small animal PET imaging system with 1 microliter volume resolution. IEEE Trans Nucl Sci. 2004; 51:757-763.

27. Tai YC, Chatziioannou AF, Yang YF, et al. MicroPET II: design, development and initial performance of an improved microPET scanner for small-animal imaging. Phys Med Biol. 2003;48:1519-1537.

28. Miyaoka RS, Janes ML, Lee K, et al. Design overview and preliminary results for the micro crystal element scanner (MiCES) [abstract]. J Nucl Med. 2003;44 (suppl):160P.
29. Berard P, Bergeron M, Pepin CM, et al. Development of a 64-channel APD detector module with individual pixel readout for submillimetre spatial resolution in PET. Nucl Instrum Meth A. 2009;610:20-23.

30. Song TY, Wu HY, Komarov S, Siegel SB, Tai YC. A sub-millimeter resolution PET detector module using a multi-pixel photon counter array. Phys Med Biol. 2010;55:2573-2587.

31. Habte F, Foudray AMK, Olcott PD, Levin CS. Effects of system geometry and other physical factors on photon sensitivity of high-resolution positron emission tomography. Phys Med Biol. 2007;52:3753-3772.

32. Bao Q, Newport D, Chen M, Stout DB, Chatziioannou AF. Performance evaluation of the Inveon dedicated PET preclinical tomograph based on the NEMA NU-4 standards. J Nucl Med. 2009;50:401-408.

33. Jakoby BW, Bercier Y, Watson CC, Bendriem B, Townsend DW. Performance characteristics of a new LSO PET/CT scanner with extended axial field-of-view and PSF reconstruction. IEEE Transactions Nucl Sci. 2009;56:633-639.

34. Performance Measurements of Small Animal Positron Emission Tomographs (PETs). Rosslyn, VA: National Electrical Manufacturers Association; 2008. NU 2-2008.

35. Performance Measurements of Positron Emission Tomographs. Rosslyn, VA: National Electrical Manufacturers Association; 2001.

36. Jakoby BW, Bercier Y, Conti M, Casey ME, Bendriem B, Townsend DW. Physical and clinical performance of the mCT time-of-flight PET/CT scanner. Phys Med Biol. 2011;56:2375-2389.

37. Yao R, Seidel J, Liow JS, Green MV. Attenuation correction for the NIH ATLAS small animal PET scanner. IEEE Trans Nucl Sci. 2005;52:664-668.

38. Yao R, Seidel J, Johnson CA, Daube-Witherspoon ME, Green MV, Carson RE. Performance characteristics of the 3-D OSEM algorithm in the reconstruction of small animal PET images. IEEE Trans Med Imaging. 2000;19:798-804.

39. Zaidi H, Koral K. Scatter modelling and compensation in emission tomography. Eur J Nucl Med Mol Imaging. 2004;31:761-782.

40. Vaska P, Rubins DJ, Alexoff DL, Schiffer WK. Quantitative imaging with the micro-PET small-animal PET tomograph. Int Rev Neurobiol. 2006;73:191-218.

41. Cherry SR. Multimodality imaging: beyond PET/CT and SPECT/CT. Semin Nucl Med. 2009;39:348-353.

42. Stout DB, Chatziioannou AF, Lawson TP, Silverman RW, Gambhir SS, Phelps ME. Small animal imaging center design: the facility at the UCLA Crump Institute for Molecular Imaging. Mol Imaging Biol. 2005;7:393-402.

43. Ametamey SM, Honer M, Schubiger PA. Molecular imaging with PET. Chem Rev. 2008;108:1501-1516

44. Michalski M, Chen X. Molecular imaging in cancer treatment. Eur J Nucl Med Mol Imaging. 2011;38:358-377.

45. Zhu A, Shim H. Current molecular imaging positron emitting radiotracers in oncology. Nucl Med Mol Imaging. 2011;45:1-14.

46. Gambhir SS, Czernin J, Schwimmer J, Silverman DHS, Coleman RE, Phelps ME. A tabulated summary of the FDG PET literature. J Nucl Med. 2001;42(suppl):1S-93S.

47. Bading JR, Shields AF. Imaging of cell proliferation: status and prospects. J Nucl Med. 2008;49(suppl 2):64S-80S.

48. Blasberg R. PET imaging of gene expression. Eur J Cancer. 2002;38:2137-2146.

49. Gambhir SS, Herschman HR, Cherry SR, et al. Imaging transgene expression with radionuclide imaging technologies. Neoplasia. 2000;2:118-138.

50. Niu G, Chen X. PET imaging of angiogenesis. PET Clin. 2009;4:17-38.

51. Dehdashti F, Holland JP, Lewis JS. Assessing tumor hypoxia by positron emission tomography with Cu-ATSM. Q J Nucl Med Mol Imaging. 2009;53:193-200.

52. Lapi SE, Voller TF, Welch MJ. PET imaging of hypoxia. PET Clin. 2009;4: 39-47.

53. Murakami Y, Takamatsu H, Taki J, et al. F-18-labelled annexin V: a PET tracer for apoptosis imaging. Eur J Nucl Med Mol Imaging. 2004;31:469-474.

54. Madar I, Huang Y, Ravert H, et al. Detection and quantification of the evolution dynamics of apoptosis using the PET voltage sensor ${ }^{18} \mathrm{~F}$-fluorobenzyl triphenyl phosphonium. J Nucl Med. 2009;50:774-780.

55. Lecomte R, Croteau E, Gauthier ME, et al. Cardiac PET imaging of blood flow, metabolism, and function in normal and infarcted rats. IEEE Trans Nucl Sci. 2004;51:696-704.

56. Germano G, Kiat H, Kavanagh PB, et al. Automatic quantification of ejection fraction from gated myocardial perfusion SPECT. J Nucl Med. 1995;36:2138-2147.

57. Croteau E, Benard F, Cadorette J, et al. Quantitative gated PET for the assessment of left ventricular function in small animals. J Nucl Med. 2003;44: 1655-1661.

58. Lancelot S, Zimmer L. Small-animal positron emission tomography as a tool for neuropharmacology. Trends Pharmacol Sci. 2010;31:411-417.

59. Liow JS, Lu SY, McCarron JA, et al. Effect of a P-glycoprotein inhibitor, cyclosporin A, on the disposition in rodent brain and blood of the 5-HT1A receptor radioligand, [C-11](R)-(-)-RWAY. Synapse. 2007;61:96-105. 
60. Schulz D, Southekal S, Junnarkar SS, et al. Simultaneous assessment of rodent behavior and neurochemistry using a miniature positron emission tomograph. Nat Methods. 2011;8:347-352.

61. Vaska P, Woody CL, Schlyer DJ, et al. RatCAP: miniaturized head-mounted PET for conscious rodent brain imaging. IEEE Trans Nucl Sci. 2004;51:27182722 .

62. Kyme AZ, Zhou VW, Meikle SR, Fulton RR. Real-time 3D motion tracking for small animal brain PET. Phys Med Biol. 2008;53:2651-2666.

63. Wehrl HF, Judenhofer MS, Wiehr S, Pichler BJ. Pre-clinical PET/MR: technological advances and new perspectives in biomedical research. Eur J Nucl Med Mol Imaging. 2009;36:56-68.

64. Heiss W-D. The potential of PET/MR for brain imaging. Eur J Nucl Med Mol Imaging. 2009;36:105-112.

65. Srinivas M, Aarntzen EHJG, Bulte JWM, et al. Imaging of cellular therapies. Adv Drug Deliv Rev. 2010;62:1080-1093.

66. Judenhofer MS, Wehrl HF, Newport DF, et al. Simultaneous PET-MRI: a new approach for functional and morphological imaging. Nat Med. 2008;14: 459-465.

67. Hoehn M, Himmelreich U, Kruttwig K, Wiedermann D. Molecular and cellular MR imaging: potentials and challenges for neurological applications. J Magn Reson Imaging. 2008;27:941-954.
68. Bliss T, Guzman R, Daadi M, Steinberg GK. Cell transplantation therapy for stroke. Stroke. 2007;38:817-826.

69. Mediso Web site. Available at: http://www.mediso.com. Accessed April 25, 2012.

70. Preclinical PET SPECT CT. Carestream Web site. Available at: http://carestream.com/pet-spect-ct-imaging.html. Accessed April 25, 2012.

71. Huisman MC, Reder S, Weber AW, Ziegler SI, Schwaiger M. Performance evaluation of the Philips MOSAIC small animal PET scanner. Eur J Nucl Med Mol Imaging. 2007;34:532-540.

72. Canadas M, Embid M, Lage E, Desco M, Vaquero JJ, Perez JM. NEMA NU 42008 performance measurements of two commercial small-animal PET scanners: ClearPET and rPET-1. IEEE Transactions Nucl Sci. 2011;58:58-65.

73. Laforest R, Longford D, Siegel S, Newport DF, Yap J. Performance evaluation of the microPET ${ }^{\circledR}$-FOCUS-F120. IEEE Trans Nucl Sci. 2007;54:42-49.

74. Tai Y-C, Ruangma A, Rowland D, et al. Performance evaluation of the microPET Focus: a third-generation microPET scanner dedicated to animal imaging. $\mathrm{J}$ Nucl Med. 2005;46:455-463.

75. Pandey SK, Saijad M, Chen Y, et al Comparative positron-emission tomography (PET) imaging and phototherapeutic potential of ${ }^{124}$ I-labeled methyl-3-(1'-iodobenzyloxyethyl)pyropheophorbide-a vs the corresponding glucose and galactose conjugates. J Med Chem. 2009;52:445-455. 